\title{
Recovery Curves for Housing Reconstruction in Sri Lanka after the 2004 Indian Ocean Tsunami
}

\section{$\underline{\text { Osamu Murao }}^{1}{ }$ Hideaki Nakazato $^{1}$}

\author{
${ }^{1}$ Graduate School of Systems and Information Engineering, University of \\ Tsukuba, 1-1-1 Tennodai, Tsukuba City, Ibaraki, 305-8573 Japan, \\ (murao@risk.tsukuba.ac.jp)
}

\begin{abstract}
On the 26th of December 2004, the Tsunami damaged to five provinces in Sri Lanka and more than forty thousand people were displaced, lost or killed within a short time. After the tsunami, the Government provided three types of houses for the victims (temporary shelters, transitional houses, and permanent houses). The authors conducted several field surveys and interviews in the damaged area to investigate the recovery conditions, and obtained data set, which had been collected for 13 months since December 2004 by Rebuilding and Development Agency. It shows the construction status of transitional house and permanent house in the damaged areas. This paper demonstrates recovery curves for the transitional houses and the permanent houses. With the aim of constructing post-earthquake recovery curves for Sri Lanka, the factors of time (months) and completion ratio of building construction are used. The obtained curves quantitatively clarify the regional differences in the completion dates and processes of construction. The proposed quantitative methodology will be used for other damaged countries due to the 2004 Indian Ocean Tsunami. It means that this kind of analysis is essential for investigating post-disaster recovery process because it enables comparative studies of urban/rural planning among different types of post-disaster recovery processes throughout the world.
\end{abstract}

\section{Introduction}

1.1 Background and Purpose

As of February 2008, more than three years have passed since the 2004 Indian Ocean Tsunami struck the coastal areas of several Indian Ocean rim countries. The tsunami damaged approximately 96,000 houses in five Sri Lankan provinces, and caused the displacement, death or loss of more than 40,000 within a short time (Department of Census and Statistics, 2005). The Sri Lankan Government gradually organized the Task Force to Rebuild the Nation (TAFREN), Rebuilding and Development Agency (RADA), and Tsunami Housing Reconstruction Unit (THRU), and provided three types of houses (temporary shelters, transitional houses, and permanent houses) to support the victims (Ministry of Finance and Planning and the Reconstruction \& Development Agency, 2006).

The authors previously conducted several field surveys and interviews in the affected areas to investigate the recovery activities, and several regional differences in these efforts were clearly observed (Nakazato and Murao, 2007). It is generally considered important to clarify the relationship between the recovery process and policy, either being implemented or planned, after disasters in discussions concerning future post-disaster recovery initiatives. However, such clarifications may be difficult by several factors: 1) long-term recovery observations including field surveys, which are necessary for collecting data, entail considerable time and cost; 2) even if statistical data has been compiled by governments, accessing such data is often difficult, and, 3) quantitative evaluations of any recovery process is complicated by diverse social phenomena.

This paper aims to develop a methodology employing recovery curves to assess both transitional and permanent housing in Sri Lanka so as to solve the problems associated with the before-mentioned difficulty of quantitative comparison of the recovery process.

\subsection{Previous Research}

This paper has two academic aspects; one is concerned with regional recovery research related to the 2004 Sumatra Tsunami, and the other relates to the general development 
methodology employed to quantitatively describe the recovery process after disasters. Regarding the former, numerous studies were published after the tsunami; however, with the exception of research conducted by the authors (Murao and Nakazato, 2006; and Nakazato and Murao, 2007), few of these studies employed regional comparisons of recovery in Sri Lanka. From the viewpoint of the latter aspect, that of quantitative descriptions of recovery, Murao et al. (2007) attempted to construct recovery curves dealing with the recovery process in Chi-Chi which was damaged by the 1999 Taiwan Earthquake. This paper therefore also attempts to apply the methodology developed for Chi-Chi to Sri Lanka for improvement.

\section{Method}

The following procedure was employed to construct post-tsunami recovery curves for Sri Lanka.

\subsection{Data Used}

First, it is necessary to assess the status of building construction in Sri Lanka. The authors obtained a dataset that had been compiled over a 15-month period starting from December 2004 by TAFREN and RADA. The database gives the construction status of more than 56,000 transitional houses and 28,000 permanent houses in the damaged areas (RADA, 2005 and 2006). It is difficult to establish the definition of "recovery" because it contains physical environment such as lifeline, social system, and individual recovery such as livelihood conditions. In this study, the authors focus on the building recovery process as one of the main factors to evaluate individual post disaster recovery conditions. The used data is the number of necessary buildings for victims estimated by the government based on the damage survey conducted after the tsunami, which was considered the displaced, lost or killed, and anticipated resettlements at the long-term recovery stage. Hence, we presumed that to reach the total number of the buildings represents the state of full recovery in a region from the viewpoint of individual physical environment.

\subsection{Recovery Ratio Calculation}

In order to plot the recovery curves, it is necessary to normalize the recovery condition of damaged areas of varying size. This was done by comparing the recovery ratio of the number of buildings constructed per month to the total number of completed buildings as of February 2006.

\subsection{Selection of Optimal Recovery Curve}

For the time period of 15 months, the cumulative ratio of building completion is assumed to be fitted a sigmoid curve such as Cumulative Normal Distribution curve, Logistic curve, or Gompertz curve. Curves showing the highest correlation with observed data were considered to represent the most optimal recovery curve.

\subsection{Development of the Recovery Curves}

Once transitional and permanent houses were selected, recovery curves were then plotted for each of the surveyed districts in Sri Lanka.

\section{Sample Data of Building Construction}

Fig. 1 shows the recovery process in Sri Lanka calculated by the cumulative number of completed (a) transitional houses and (b) permanent houses based on statistical data. Fig. 1(a) shows that the first transitional houses were completed in March 2005, with the number increasing markedly until August 2005 and remaining relatively constant thereafter until December 2005. Conversely, Fig. 1(b) shows that the provision of permanent houses began in April 2005, and increased more gradually in number relative to the number of transitional houses. These figures clearly demonstrate the disparity in the rates of completion of transitional and permanent houses. 


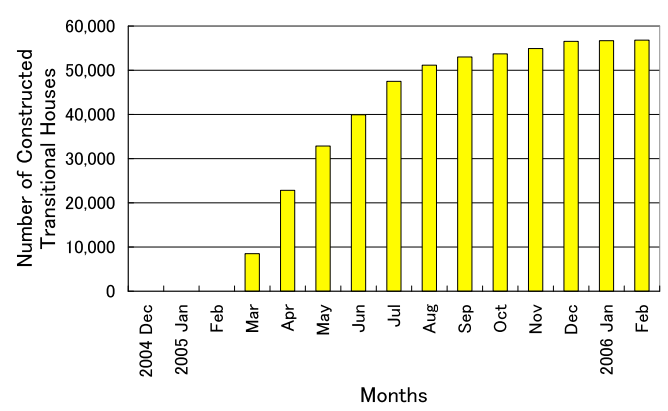

a. Transitional houses

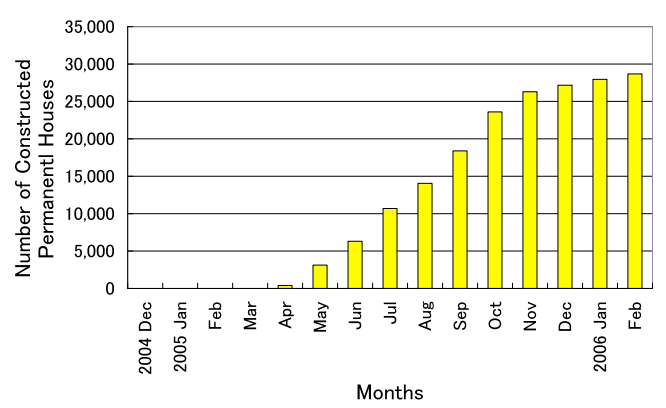

b. Permanent houses

Fig. 1 Rate of house construction in Sri Lanka following the 2004 tsunami

\section{Selection of Optimal Recovery Curve Using a Sigmoid Function}

Optimal approximate recovery curves were then selected for the two types of the houses. Assuming that the relationship between elapsed time and recovery ratio closely fits a sigmoid curve, we considered three kinds of Sigmoid Curves; Cumulative Normal Distribution curve, Logistic curve, and Gompertz curve.

\subsection{Plotting of Recovery Curves}

The factors of time (months) and the ratio of building completion were used to draft the recovery functions. The time period starts in December 2004, with January 2005 being regarded as month " 1 ", and extends over 14 months until February 2006. The ratio of building completion for a given time period is calculated based on the total amount of completed buildings. For a time period of $t$ (months), the cumulative ratio of building completion $R(t)$ can be described by the Cumulative Normal Distribution-, Logistic -, and Gompertz curves, using the following equations:

a. Cumulative Normal Distribution curve

$$
R(t)=\Phi((t-\lambda) / \zeta)
$$

b. Logistic curve

$$
R(t)=\frac{1}{1+a \exp (-b t)}
$$

c. Gompertz curve

$$
R(t)=a^{b^{t}}
$$

where $\Phi$ represents the standard Normal Distribution, and $\lambda$ and $\zeta$ are the mean and standard deviation of $\mathrm{t}$, respectively. The two parameters $\lambda$ and $\zeta$ are determined using the least squares method on probability paper. Other parameters, $a$ and $b$, are coefficients for Eq. [2] and Eq. [3].

\subsection{Approximate Recovery Curves}

As in 4.1, the three types of approximate recovery curves were plotted as shown in Fig. 2 and Fig. 3. The figures demonstrate that the best fit for the transitional and permanent houses are the Gompertz Distribution in Fig. 2c, and the Cumulative Normal Distribution in Fig.3a, respectively. Consequently, the Gompertz curve was thus adopted for assessing recovery rates using transitional houses and the Cumulative Normal Distribution curve was employed for assessing recovery rates using the permanent houses.

This can be explained from the fact that transitional/temporary houses are necessary to be built just after the events for victims. Generally speaking, it commences to construct one or two month(s) after the event and fulfills the demand temporarily several months later. On the other hand, the construction of permanent houses can start after careful consideration by governments or stake holders according to regional circumstances. So, it is reasonable that the tendency of the construction process of transitional houses is demonstrated in a "growth curve" such as the Gompertz curve, and the curves of the permanent houses fit Cumulative 
Normal Distribution. These tendencies were demonstrated in the study of Chi-Chi by Murao et al. (2007), too.

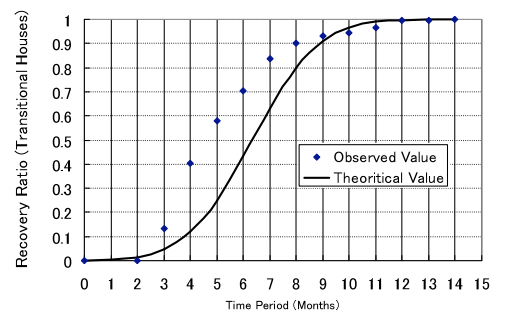

a. Cumulative Normal Distribution curve

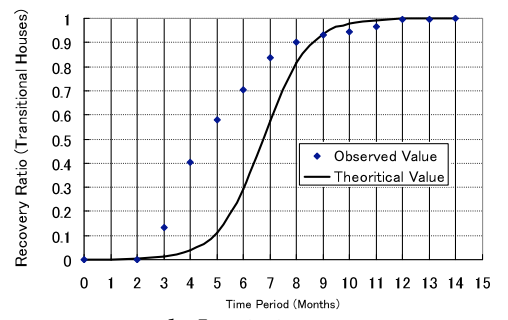

b. Logistic curve

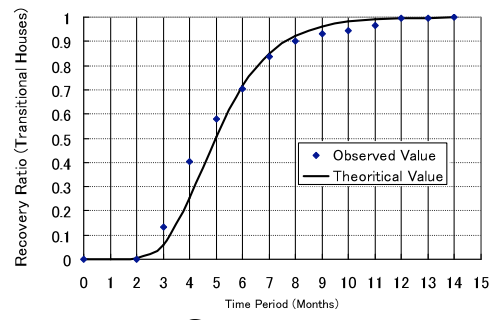

c. Gompertz curve

Fig. 2 Approximate recovery curves for observed recovery ratios for transitional houses

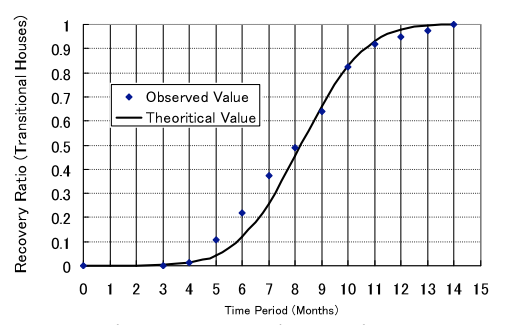

a. Cumulative Normal Distribution curve

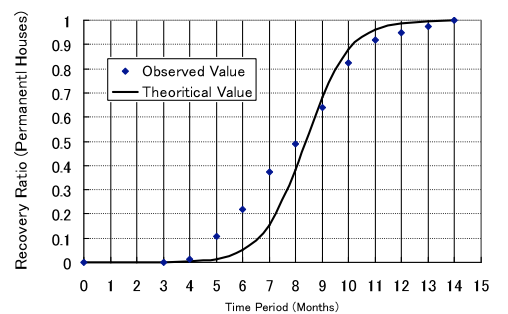

b. Logistic curve

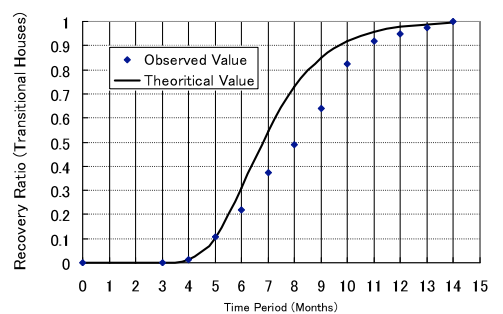

c. Gompertz curve

Fig. 3 Approximate recovery curves for observed recovery ratios for permanent houses

\section{Determination of Recovery Curves for Sri Lanka}

Recovery curves for damaged districts in Sri Lanka can now be plotted using the regional construction data for each district. However, it should be noted that the number of buildings constructed in some districts was less than that estimated for necessary construction by the Government immediately after the tsunami (Nakazato and Murao, 2007). Since the recovery curves can thus be considered to closely reflect the actual situation (Section 4.2 above), a parameter, $K$, reflecting the completion realization ratio for each district can be combined with Eqs. [1] and [3] to give Eq. [4] for the permanent houses and Eq. [5] for the transitional houses, as the final building recovery functions. In addition, Eq. [6] shows the probability density function of the Gompertz curve.

$$
\begin{aligned}
& R(t)=K \cdot \Phi((t-\lambda) / \zeta) \\
& R(t)=K a^{b^{t}} \\
& P(t)=K a^{b^{t}} b^{t} \cdot \log a \cdot \log b
\end{aligned}
$$

Finally, two different recovery curves were developed for application to all damaged districts except for Gampaha (for transitional houses) and Mullaitivu which had insufficient data. The different parameters, regional average time required for each house type, recovery curves, and probability density functions are shown in Table 2, Fig. 4, Fig. 5, and Fig. 6 respectively. In addition, a high correlation was observed between the curves developed in this study and observed data (Fig. 5), and the curves are considered to properly reflect regional recovery conditions. The findings quantitatively clarified that the average time required for the completion of transitional houses in Hambantota, Galle, and Kaluthara was less than that of the northern and eastern districts. Conversely, the time required for completion of permanent houses in Batticaloa, Jaffna, Killinochchi, Colombo, and Kaluthara were considerably longer than elsewhere in the country. Taken together, these 
findings corroborate those of a previous paper (Nakazato and Murao, 2007).

Interpretations of the recovery process vary according to the regional context. For example, the delay of permanent house construction in Trincomalee was influenced by a construction strike of December 2005 in the area. The recovery curves developed in the study will enable not only to compare the recovery processes quantitatively but also to be helpful to interpret the relationship between the process and regional context.

Table 2 Recovery curve parameters for different districts in Sri Lanka

\begin{tabular}{|c|c|c|c|c|c|c|c|c|}
\hline & \multicolumn{4}{|c|}{$\begin{array}{l}\text { Transitional Houses } \\
\text { (Gompertz Curve) }\end{array}$} & \multicolumn{4}{|c|}{$\begin{array}{c}\text { Permanent Houses } \\
\text { (Cumulative Normal Distribution Curve) }\end{array}$} \\
\hline & $a$ & $\begin{array}{ll}b \\
b\end{array}$ & $R^{2}$ & $K$ & $\lambda$ & $\zeta$ & $R^{2}$ & $K$ \\
\hline Ampara & $1.06 \mathrm{E}-10$ & 0.487 & 0.953 & 1.00 & 7.766 & 1.751 & 0.941 & 0.55 \\
\hline Batticaloa & $5.21 \mathrm{E}-12$ & 0.504 & 0.952 & 1.00 & 9.799 & 1.797 & 0.876 & 1.00 \\
\hline Trincomalee & $2.14 \mathrm{E}-12$ & 0.484 & 0.931 & 1.00 & 8.450 & 1.757 & 0.950 & 1.00 \\
\hline Galle & $2.3 \mathrm{E}-12$ & 0.409 & 0.966 & 0.91 & 7.897 & 1.879 & 0.944 & 1.00 \\
\hline Matara & $1.31 \mathrm{E}-08$ & 0.530 & 0.946 & 1.00 & 8.563 & 1.794 & 0.949 & 1.00 \\
\hline Hambantota & $4.23 \mathrm{E}-06$ & 0.495 & 0.866 & 1.00 & 6.302 & 1.347 & 0.936 & 1.00 \\
\hline Colombo & 0.000165 & 0.583 & 0.928 & 0.41 & 8.882 & 1.814 & 0.893 & 0.13 \\
\hline Gampaha & - & - & - & - & 6.423 & 1.369 & 0.806 & 0.51 \\
\hline Kalutara & $9 \mathrm{E}-07$ & 0.482 & 0.888 & 0.63 & 8.901 & 2.059 & 0.915 & 1.00 \\
\hline Jaffna & $7.3 \mathrm{E}-06$ & 0.527 & 0.885 & 1.00 & 9.034 & 1.613 & 0.871 & 1.00 \\
\hline Kilinochchi & $2.55 \mathrm{E}-05$ & 0.645 & 0.812 & 0.68 & 8.913 & 1.620 & 0.862 & 1.00 \\
\hline Mullaitivu & - & - & - & - & - & - & - & - \\
\hline Total & $3.36 \mathrm{E}-11$ & 0.489 & 0.924 & 1.00 & 8.217 & 1.878 & 0.962 & 1.00 \\
\hline
\end{tabular}

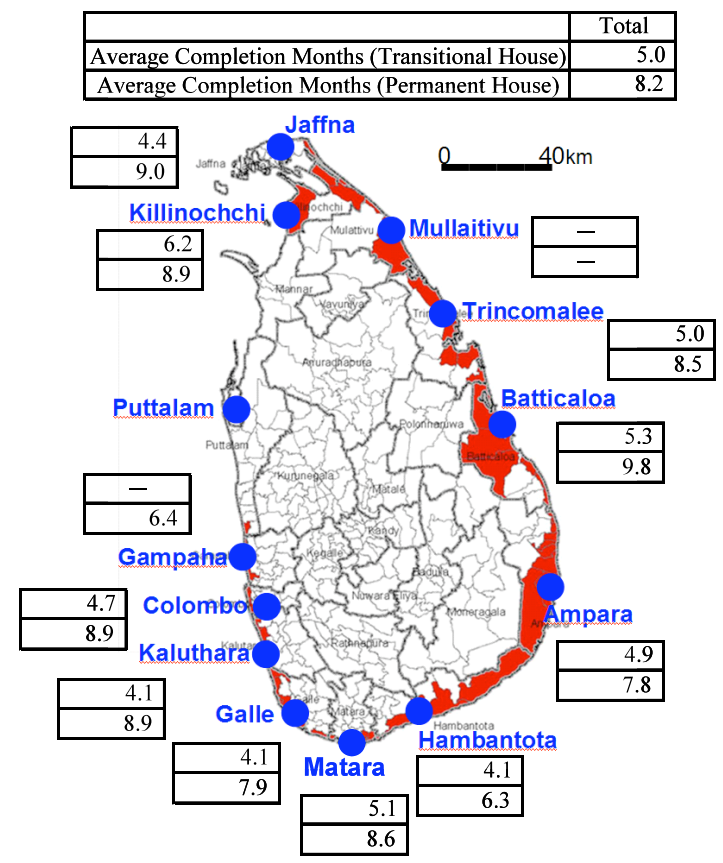

Fig. 4 Average time period required for the completion of construction in Sri Lank

\section{Conclusion}

In this study, recovery curves were developed to assess recovery from the Sumatra Tsunami using the rate of construction of both transitional and permanent houses in Sri Lanka, from the viewpoint of regional physical environment. It was found that a Gompertz Distribution was the best fit for transitional house data, while Cumulative Normal Distribution most closely matched the distribution of newly constructed permanent houses in Sri Lanka. The recovery curves could be used to quantitatively assess the regional differences in recovery efforts among the damaged areas throughout the country.

The procedure described in this study for constructing recovery curves could be adapted for use as a general methodology for evaluating and comparing recovery initiatives in different regions or countries. For example, constructing recovery curves for each of the countries adversely affected by the 2004 Sumatra Tsunami could be used quantitatively compare the 
extent of recovery efforts in those countries. We never discuss the pros and cons of the conducted recovery policy and planning without quantitative comparison of the recovery process of the affected counties. The study by the authors could help to consider it. However, some problems remain. One such problem is availability of the data required for compiling the recovery curves; it spends lots of cost of time and money to obtain the long-term regional recovery data based on the individual field survey. Even if government statistical data is available, acquiring these data usually requires extensive negotiations. Another problem relates to difficulty associated with determining a suitable denominator for calculating recovery ratios; in this study it was assumed that the construction of buildings had almost been completed in February 2006 and the total number of the completed buildings at the time was therefore used as the denominator for the recovery ratio. In addition, social context and other elements should also be considered when developing the recovery curves for other cases.
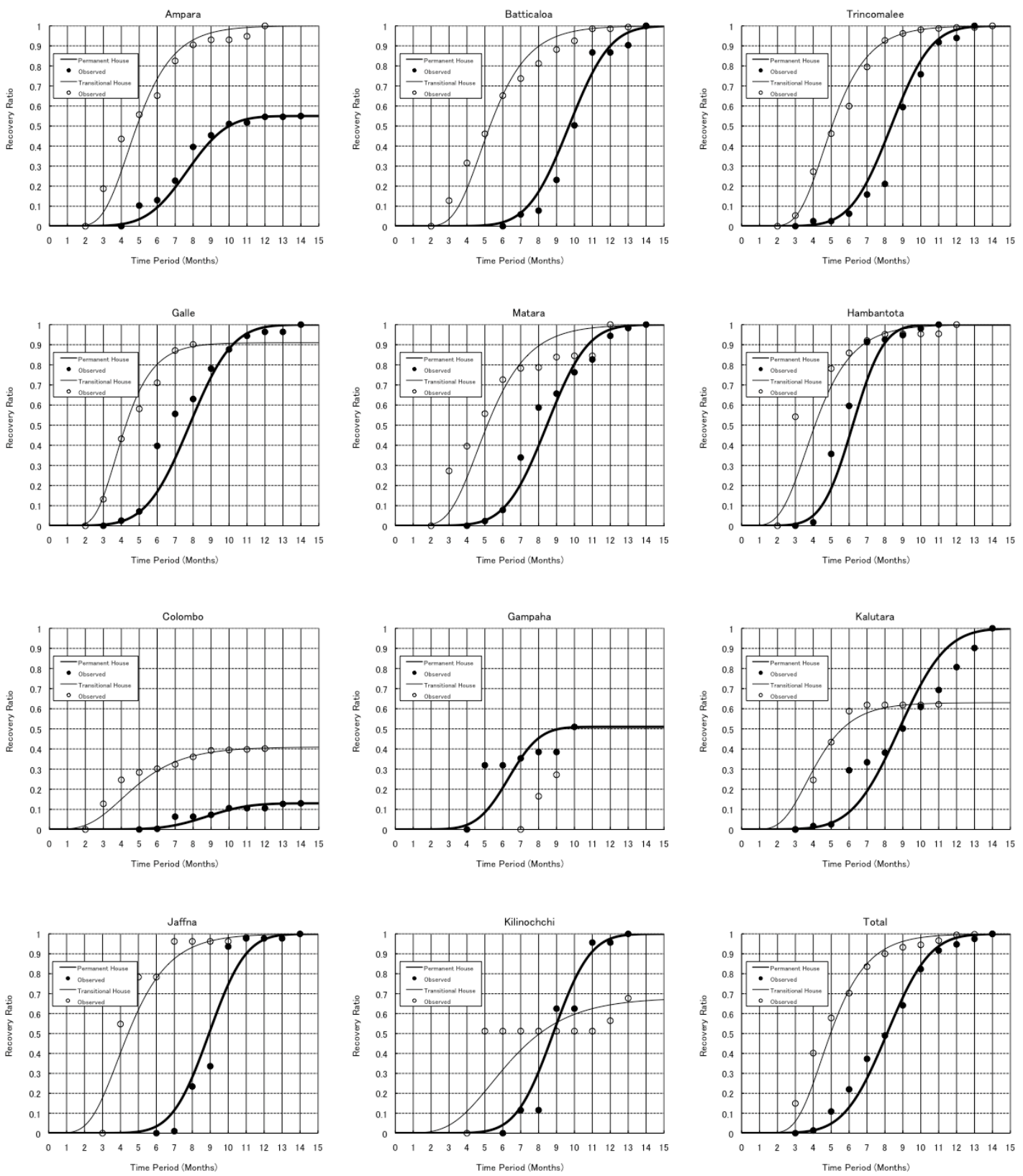

Fig. 5 Recovery curves for different building types in Sri Lanka 

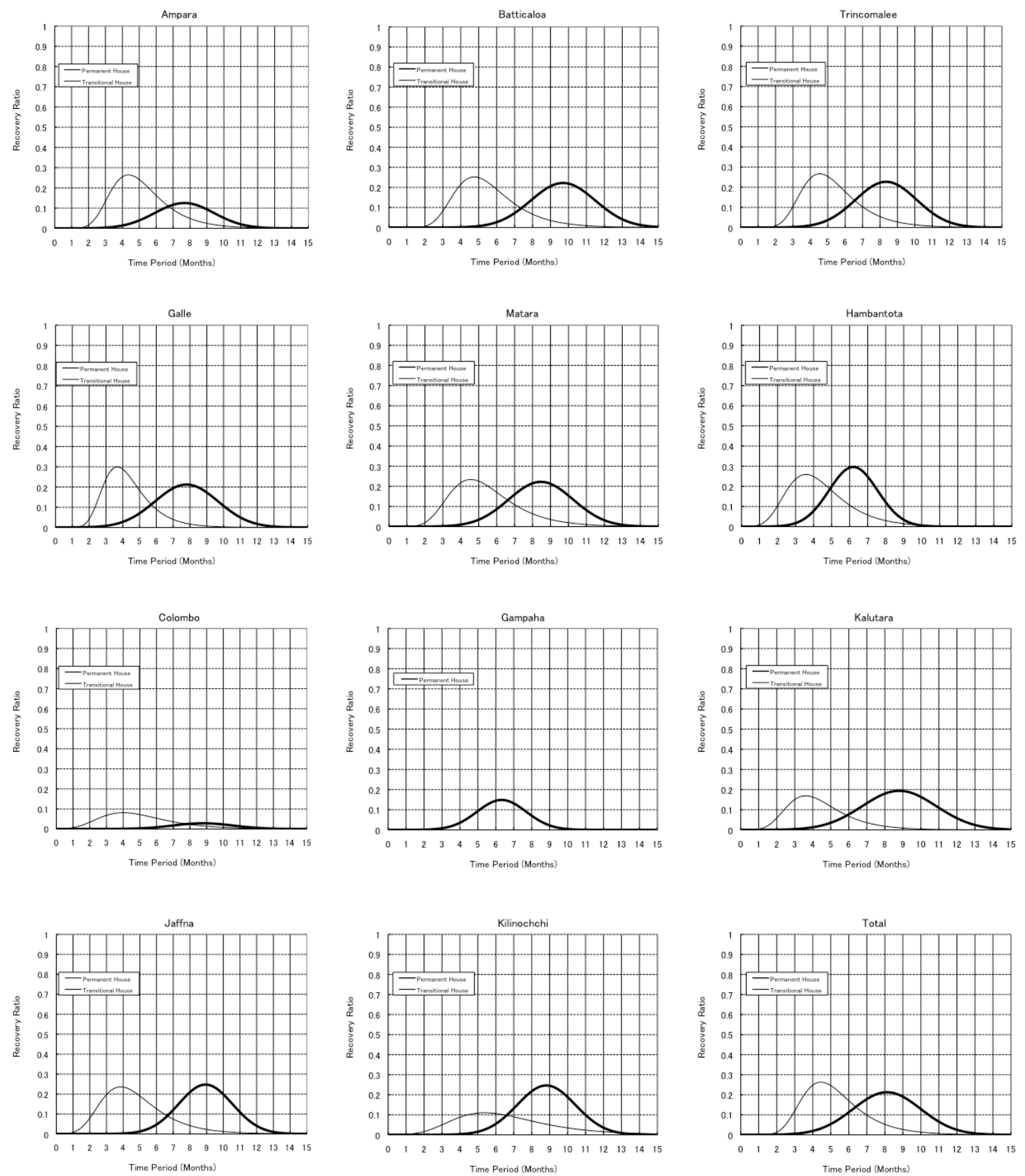

Fig. 6 Probability density functions for the completion of building construction in Sri Lanka relative to time period (months) after the 2004 Tsunami

\section{References}

Department of Census and Statistics, Census of Persons, Housing Units and Other Buildings affected by Tsunami, 26th December 2004, 2005.

Ministry of Finance and Planning and the Reconstruction \& Development Agency (RADA), Post-Tsunami Recovery and Reconstruction, 2006.

Murao, O. and Nakazato, H., Regional Characteristics of Building Damage and Reconstruction Condition in Sri Lanka due to 2004 Sumatra Tsunami, Asia Oceania Geosciences Society, the 3rd Annual Meeting (CD-ROM), No. 59-SE-A1161, 927, Singapore. 2006.7

Murao, O., Mitsuda, Y., Miyamoto, A., Sasaki, T., Nakazato, H., and Hayashi, T., Recovery Curves and Digital City of Chi-Chi as urban recovery digital archives, Proceedings of the 2nd International Conference on Urban Disaster Reduction (CD-ROM), Taipei, Taiwan. 2007.11

Nakazato, H. and Murao, O., Report on the Tsunami housing reconstruction process and 
problems in Sri Lanka affected by 2004 Sumatra Tsunami, Proceedings of the 2nd International Conference on Urban Disaster Reduction (CD-ROM), Taipei, Taiwan, 2007.11

Rebuilding and Development Agency (RADA), Progress Report, 2005

Rebuilding and Development Agency (RADA), Progress Report, 2006

\section{Acknowledgements}

This paper is supported by "Restoration Program from Giant Earthquakes and Tsunamis, Granted by MEXT. The authors are grateful for the assistance of Sri Lankan Governments, Mr. Nihal Rpasinghe (CECB), Dr. Srikantha Herath (UNU), and Navindra De Silva. 